\title{
Learning Al-Qur'an Hadith Subjects Through Problem Solving Strategy
}

\author{
Regita Vita Cahyani \\ Universitas Muhammadiyah Malang \\ tagita29@gmail.com \\ Romelah \\ Universitas Muhammadiyah Malang \\ romlah@umm.ac.id \\ Hadi Nur Taufiq \\ Universitas Muhammadiyah Malang \\ hntaufiq@umm.ac.id
}

\begin{abstract}
This research aims to find out the study of the Qur'an Hadith through problem solving strategy in MTs Surya Buana Malang. The focus of the problem to be reviewed is: learning planning, learning implementation, and evaluation. This research is qualitative research. This type of research is field research with data collection techniques using interview, observations and documentations. From the results of this study, it can be concluded that the learning of the Qur'an Hadith consists of: 1. Learning planning of the Qur'an Hadith through problem solving strategy consists of syllabus and Learning Implementation Plan. 2. The implementation of the learning of the Qur'an Hadith, opening the lesson by giving important points and reviewing the material, presenting the material then closing the lesson by reviewing, for the implementation of problem solving strategy on the material of the Qur'an Hadith from the results of this study is declared successful. 3. Evaluation of the learning of the Qur'an Hadith, the teacher uses several types of evaluations such as multiple choice, essay or stuffing, and quiz, the teacher behaves ma'fu (tolerance) so that his students can improve the evaluation value.
\end{abstract}

Keywords: Learning, Qur'an Hadith, Problem Solving Strategy

Abstrak: Penelitian ini bertujuan untuk mengetahui pembelajaran Al-Qur'an Hadits melalui strategi problem solving di MTs Surya Buana Malang. Fokus masalah yang akan dikaji adalah: perencanaan pembelajaran, pelaksanaan pembelajaran dan evaluasi. Penelitian ini merupakan penelitian kualitatif. Jenis penelitian ini adalah field research dengan tehnik pengumpulan data menggunakan wawancara, observasi dan dokumentasi. Dari hasil penelitian ini, dapat disimmpulkan pembelajaran Al-Qur'an Hadits terdiri dari: 1. Perencanaan pembelajaran AlQur'an Hadits melalui strategi problem solving terdiri dari silabus dan Rencana Pelaksanaan Pembelajaran. 2. Pelaksanaan pembelajaran Al-Qur'an Hadits, membuka pelajaran dengan memberi poin-poin penting dan review materi, menyajikan materi kemudian menutup pelajaran dengan meninjau kembali, untuk pelaksanaan strategi problem solving pada materi AlQur'an Hadits dari hasil penelitian ini dinyatakan berhasil. 3. Evaluasi pembelajaran Al-Qur'an Hadits, guru menggunakan beberapa jenis evaluasi seperti pilihan ganda, essay atau isian, dan quiz, guru bersikap ma'fu (toleransi) agar anak didiknya dapat memperbaiki nilai evaluasinya.

Kata Kunci: Pembelajaran, Al-Qur'an Hadits, Strategi Problem Solving 


\section{PENDAHULUAN}

Allah SWT telah menganugerahkan kepada manusia (umat Islam) suatu kitab suci yakni Al-Qur'an. Al-Qur'an digunakan sebagai petunjuk bagi manusia (Hudan Linnas) yang menjelaskan tentang konsep dan tata cara hidup yang mengantarkan manusia pada keselamatan, kemudian sebagai petunjuk terperinci (Bayyinat Minal Huda) tentang rincian petunjuk tentang realitas dan hukumhukum praktis untuk menyelesaikan perkara-perkara di antara manusia, dan pembeda (Al-Furqan) yaitu membedakan atau memisahkan antara yang hak dan bathil sehingga tidak bercampur aduk. ${ }^{1}$

Kewajiban muslim terhadap Al-Qur'an di antaranya Mengimani, membaca, memahami dan mengamalkannya. ${ }^{2}$ Kewajiban-kewajiban tersebut merupakan salah satu syarat menjadi seorang muslim yang utuh. Mengimani berarti bahwa ia harus percaya bahwa Al-Qur'an merupakan firman dari Allah, kemudian ia membacanya agar mendapatkan pahala, setelah membaca, kita diwajibkan memahaminya dengan cara membaca terjemahan dan mempelajarinya. Dan yang terakhir mengamalkannya walau hanya satu ayat. Permasalahan umum yang dihadapi oleh setiap muslim terhadap Al-Qur'an yakni tidak semua orang mampu memahami hakikat isinya dan melaksanakannya. Mayoritas umat Islam memiliki keimanan yang statis terhadap Al-Qur'an. Alih-alih membaca, memahami dan mengamalkannya, Al-Qur'an sekedar dijadikan barang pajangan atau dijadikan mahar dalam perkawinan. Banyak kaum muslim yang mengaku beriman kepada Al-Qur'an, tetapi tindaktanduknya sangat jauh dari apa yang Allah firmankan. ${ }^{3}$

Pendidikan agama Islam adalah pendidikan dengan melalui ajaran-ajaran Islam, yaitu berupa bimbingan dan asuhan terhadap anak didik agar nantinya setelah selesai dari pendidikan ia dapat memahami, menghayati dan mengamalkan ajaran-ajaran agama Islam yang telah diyakininya secara menyeluruh, serta menjadikan agama Islam itu sebagai suatu pandangan hidupnya demi keselamatan dan kesejahteraan hidup di dunia maupun di akhirat kelak. Pendidikan agama merupakan bagian pendidikan yang amat penting yang berkenaan dengan aspek-aspek sikap dan nilai, antara lain akhlak dan

${ }^{1}$ Amirulloh Syarbini dan Sumantri Jamhari, “Kedabsyatan Membaca Al-Qur'an”, (Bandung: 2012), hal.38

\footnotetext{
${ }^{2}$ Ibid, .... hal.48

${ }^{3}$ Irja Nasrullah, "Resep Hidup Bahagia Manurut Al-Qur'an”, (Pustaka Alvabet: 2019), hal.15
} 
keagamaan. Oleh karena itu pendidikan agama juga menjadi tanggung jawab keluarga, masyarakat dan pemerintah. ${ }^{4}$

Permasalahan khusus yang dihadapi sebagai guru dalam melaksanakan pembelajaran mata pelajaran mata pelajaran Al-Qur'an Hadits yaitu guru tidak menentukan strategi pembelajaran sebelum pembelajaran dimulai, kurang bervariasinya penggunaan metode pembelajaran, media yang digunakan kurang tepat dengan materi yang diajarkan, dan tidak ada titik temu antara strategi, metode, media, yang diajarkan.

Mata pelajaran Al-Qur'an hadits merupakan salah satu bagian dari mata pelajaran pendidikan agama islam yang digunakan sebagai wahana pemberiak pengetahuan, bimbingan dan pengembangan kepada murid agar dapat memahami, meyakini dan menghayati kebenaran ajaran islam serta diaplikasikan dalam kehidupan sehari-hari. Oleh karena itu, mata pelajaran ini sangat penting diajarkan kepada murid sebagai bahan pelajaran di sekolah. ${ }^{5}$ Realita yang terjadi bahwa pembelajaran al-qur'an hadits sebagian besar siswa mempunyai kelemahan yang sama yaitu siswa kurang aktif dalam mengikuti proses pembelajaran, siswa cenderung pasif dan kurang termotivasi dalam belajar di kelas. $^{6}$

Pembelajaran pendidikan agama Islam saat ini bukanlah mata pelajaran utama khususnya pada sekolah-sekolah yang berlabel umum. Sehingga pelajaran ini tidak dianggap terlalu penting bagi sebagian siswa. Sehingga selama proses pembelajaran siswa tidak menunjukkan keaktifannya. ${ }^{7}$

Solusi agar materi Al-Qur'an Hadits dapat tersampaikan dengan baik kepada anak didik baik itu untuk semua guru PAI dan untuk guru Al-Qur'an Hadits yakni menggunakan strategi pembelajaran yang tepat dan metode yang variatif, salah satu alternatif yang dapat digunakan yaitu menggunakan strategi Problem Solving baik dilakukan secara individu maupun berkelompok. Serta ada kontrol dari orang tua ketika anak didik di rumah, orang tua berperan untuk

${ }^{4}$ Saddam Husein, Radiudin Alfian Sangadji, dan Laganti Salayar, "Urgensi Pembelajaran Al-Qur'an Hadist terhadap Prestasi Belajar Peserta Didik di MTs Nurul Ikhlas Kalapa Dua Seram Bagian Barat”, Al-iltizam, Vol.3,No.1, (Mei 2018), hal.3

5 Millata Zamana dan Siti Rahmah, "Kreativitas Guru dalam Penerapan Metode Pembelajaran Al-Qur'an Hadits di MIN Rukoh Banda Aceh”, Jurnal Tunas Bangsa, Vol.5, No.2, (Agustus 2018), hal.2

${ }^{6}$ Harmoni, "Implementasi Pembelajaran Al-Qur'an Hadits Terhadap Minat Belajar Peserta Didik", Jurnal Pemikiran dan Pengembangan Pembelajaran, Vol.2, No.1, (Januari-April), hal.2

7 Muslim Afandi, dan Zuraidah. "Kesiapan, Gaya Belajar dan Keaktifan Siswa Pada Pembelajaran Pendidikan Agama Islam di SMPN Bangkinang Kota". Jurnal Belajea LAIN Curup. Vol 5. No 2. 2020), hal.6 
mambantu anak me-review lagi materi Al-Qur'an Hadits yang telah diajarkan oleh guru yang tentunya sudah didiskusikan dengan pihak guru.

Menurut Pepkin dalam Shoimin Problem Solving adalah suatu strategi pembelajaran yang terpusat pada pengajaran dan keterampilan memecahkan masalah, diikuti dengan penguatan keterampilan. ${ }^{8}$ Menurut Abdul Majid langkah-langkah yang harus ditempuh dalam problem solving method ada lima, yakni; pertama, Adanya masalah yang jelas yang harus dipecahkan. Masalah ini harus tumbuh sesuai dengan kemampuan siswa. Kedua, Mencari data atau keterangan yang dapat dapat digunakan untuk memecahkan masalah tersebut. Ketiga, Menetapkan jawaban sementara dari masalah tersebut. Keempat, Menguji kebenaran jawaban sementara tersebut. Kelima, Menarik kesimpulan.'

Bertolak belakang pada uraian di atas, maka peneliti tertarik untuk melakukan penelitian dengan alasan yakni mata pelajaran Al-Qur'an selalu menjadi mata pelajaran yang memiliki banyak hal yang diajarkan. Kompetensi yang diajarkan di dalam pelajaran tersebut yaitu kemampuan membaca, menulis, menghafal, menerjemahkan, memahami dan mengamalkan baik Al-Qur'an maupun Hadits. Mempelajari Al-Qur'an Hadis bertujuan agar peserta didik gemar membaca AlQur'an dan Hadis dengan benar, serta mempelajarinya, memahami, meyakini kebenarannya, dan mengamalkan ajaran-ajaran yang terkandung didalamnya sebagai petunjuk dan pedoman dalam seluruh aspek kehidupan. Dengan demikian pembelajaran Al-Qur'an Hadis memiiki fungsi lebih istimewa dibanding dengan yang lain dalam hal mempelajari Al-Qur'an. ${ }^{10}$

Untuk itu, agar pembelajaran menjadi efisien dan praktis, pembelajaran berdasarkan masalah dengan menganalisis permasalahan pada materi bisa dijadikan rujukan. Keterampilan memecahkan masalah siswa dapat diketahui ketika mereka dihadapkan pada berbagai masalah. Ada siswa yang memilih menghadapi masalahnya dan ada siswa yang memilih menghindari masalah. Bagi siswa yang memilih menghadapi masalah, siswa dapat dikatakan memiliki salah satu keterampilan memecahkan masalah, yaitu komponen motivasi. Meskipun komponen ini belum terwujud secara aktual, tetapi komponen ini

${ }^{8}$ Isnu Hidayat, “50 Strategi Pembelajaran Populer” (Yogyakarta:2019), hal.128

9 Chotibul Muttaqin dan Zaenal Arifin, "Babtsul Masail sebagai Problem Solving Method dalam Pembelajaran Fikih Kontekstual”, Attaqwa: Jurnal Ilmu Pendidikan Islam, Vol.16, No.1, (Maret 2020), hal.19

10 Ar-Rasikh, "Pembelajaran Al-Qur'an Hadits di Madrasah Ibtidaiyah: Studi Multisitus padaa MIN Model Sesela dan Madrasah Ibtidaiyah At-Tahzib”, Jurnal Penelitian Keislaman, Vol.15, No.1 (2019), hal.15 
memiliki potensi untuk menumbuhkan komponen keterampilan memecahkan masalah lainnya melalui proses latihan. ${ }^{11}$

\section{METODE PENELITIAN}

Dalam hal ini, jenis penelitian yang digunakan oleh peneliti adalah jenis penelitian lapangan (Field Research). Penelitian lapangan merupakan penelitian kualitatif dimana peneliti mengamati dan berpartisipasi secara langsung dalam penelitian skala sosial kecil dan mengamati budaya setempat. Peneliti secara individu berbicara dan mengamati langsung orang-orang yang sedang ditelitinya. ${ }^{12}$ Disebut penelitian lapangan karena penelti harus terjun langsung ke lapangan, terlibat dengan masyarakat setempat. Terlibat dengan partisipan atau masyarakat berarti turut merasakan apa yang mereka rasakan dan sekaligus juga mendapatkan gambaran komprehensif tentang situasi setempat. ${ }^{13}$

Jenis penelitian digunakan untuk mengamati dan melihat secara langsung proses pembelajaran Al-Qur'an Hadits melalui strategi problem solving. Sumber atau partisipan dalam penelitian adalah guru, kepala madrasah dan siswa-siswa. Dalam mendapatkan hasil data yang diharapkan, tehnik pengumpulan data pada penelitian ini menggunakan tiga cara:

\section{Observasi}

Dalam hal observasi ini, peneliti menggunakan observasi partisipan. Orang yang mengadakan observasi turut ambil bagian dalam kehidupan orangorang yang diobservasi. Umumnya observasi partisipan dilakukan untuk penelitian yang bersifat eksploratif. Menyelidiki perilaku individu dalam situasi sosial seperti cara hidup, hubungan sosial dalam masyarakat, dan lain-lain. ${ }^{14}$

\section{Wawancara}

Peneliti dapat melakukan face to face interview dengan partisipan, mewawancarai mereka dengan telepon, atau terlibat dalam focus group interview yang terdiri dari enam sampai delapan partisipan perkelompok. Wawancarawawancara seperti ini tentu saja memerlukan pertanyaan-pertanyaan yang secara

11 Miftahus Surur, dkk "Keefektifan Problem Solving Strategy (PSS) Untuk Meningkatkan Keterampilan Memecahkan Masalah pada Siswa SMP, Jurnal Pendidikan, Vol.1, No.11, (November 2016), hal.2

${ }^{12}$ Fadlun Maros, dkk "Penelitian Lapangan (Field Research)" (Makalah Fakultas Ilmu Sosial dan Ilmu Politik Universitas Sumatera Utara, Sumatera 2016), hal.6

${ }^{13}$ Conny.R.Semiawan, "Metode Penelitian Kualitatif” (Cikarang:2010), hal.9

${ }^{14}$ Hasyim Hasanah, “Teknik-teknik Observasi”, Jurnal at-Taqaddum, Vol 8,No.01, (2016) hal.36 
umum tidak terstruktur dan bersifat terbuka yang dirancang untuk memunculkan pandangan dan opini dari para partisipan. ${ }^{15}$

\section{Dokumentasi}

"Menurut Gottschalk menyatakan bahwa dokumen dalam pengertiannya yang lebih luas berupa setiap proses pembuktian yang didasarkan atas jenis sumber apapun, baik itu yang bersifat tulisan, lisan, gambaran, atau arkeologis". ${ }^{16}$

Dan untuk tehnik analisa data, peneliti berkaca pada Miles dan Huberman yang beranggapan bahwa analisis terdiri dari tiga alur kegiatan yang terjadi secara bersamaan yaitu: reduksi data, penyajian data, dan penarikan kesimpulan/verifikasi. Pada penelitian kualitatif, analisis data sudah dilakukan bahkan sebelum peneliti memasuki lapangan. Analisis dilakukan terhadap data hasil studi pendahuluan atau data sekunder, yang akan digunakan untuk menentukan fokus penelitian, dan akan berkembang setelah peneliti masuk dan di lapangan. Namun demikian, fokus peneliti ini masih bersifat sementara, dan akan berkembang setelah peneliti masuk lapangan. ${ }^{17}$

\section{HASIL dan PEMBAHASAN}

Pendidikan Agama Islam merupakan mata pelajaran wajib yang harus diajarkan kepada peserta didik. Namun masih banyak dijumpai bahwa pendidikan agama islam belum mampu mencapai tujuan dari Pendidikan Agama Islam. Tujuan Pendidikan Agama Islama adalah menumbuhkan dan menigkatkan keimanan melalui pengetahuan, penghayatan, pengalaman, dan juga pengamalan atas pengetahuan yang ia peroleh sebagai wujud manusia yang beriman. ${ }^{18}$ Maka dari itu, penggunaan metode maupun strategi yang tepat oleh guru sangat berpengaruh pada ketercapaian tujuan dari Pendidikan Agama Islam.

Dalam penelitian ini, ada beberapa hal yang harus diperhatikan oleh guru saat menyampaikan materi pembelajaran, di antaranya: perencanaan pembelajaran, pelaksanaan pembelajaran dan evaluasi pembelajaran. guru maupun kepala madrasah MTs Surya Buana dalam hal perencanaan

\footnotetext{
${ }^{15}$ Rukin, Metodologi Penelitian Kualitatif, (Takalar: 2019), hal.254

${ }_{16}$ Muh Fitrah, Luthfiyah, Metodologi Penelitian: Penelitian Kualitatif, Tindakan Kelas \& Studi Kasus, (Sukabumi: CV Jejak, 2017), hal. 74

17 Anggito, Albi dan Johan Setiawan. 2018. Metodologi Penelitian Kualitatif. Sukabumi: CV Jejak. Hlm 240-241

${ }^{18}$ Hidayatul muamanah dan Suyadi. "Pelaksanaan Teori Belajar Bermakna David Ausebel Dalam Pembelajaran Pendidikan Agama Islam". Jurnal Belajea IAIN Curup. Vol 5. No.1. 2020. Hlm 4
} 
pembelajaran mengacu pada dua hal yaitu RPP (Rencana Pelaksanaan Pembelajaran) dan silabus. Kemudian untuk pelaksanaan pembelajaran, guru mata pelajaran $\mathrm{Al}$-Qur'an Hadits memulai dengan pembukaan, penyajian materi dan penutup, dan terakhir untuk evaluasi yang digunakan berupa quiz, essay, pilihan ganda, dan penilaian sejawat.

\section{Perencanaan Pembelajaran}

\section{Rencana PelaksanaannPembelajaran (RPP)}

Guru maupun elemen-elemennsekolah lainnya sangat mengutamakan perencanaan pembelajarannuntuk semua mata pelajaran. Terlihat bahwa sebuahnpembelajaran tidak akan berjalan dengan baik jika guru tidaknmenyiapkan perangkatnpembelajaran, seperti RPP. Setiap perencanaan pembelajaran dibuat agar dapat membantu guru. Hal itu dinamakan dengan persiapan (preparing)nsebelum guru menghadapi peserta didik. Menjadikan pembelajaranntersebut terarah dan jelas tujuan yang hendak dicapai.

\section{Silabus}

Silabus yang digunakan di MTs Surya Buana untuk kelas VII tidak berubah,nperubahan signifikan hanya terdapat pada RPP yang dibuat oleh guru setiap matanpelajaran, hal ini dikarenakan pengaruh dari keadaan dimana pandemi sedang melanda. Peneliti pun menganalisis isi dan kesesuaian antaranmateri yang diberikan dengan silabus matanpelajaran Al-Qur'an Hadits ketika guru memberikan materinpembelajaran, dan terbukti bahwanmemang tidak adanperubahan serta telahnsesuai antara silabus dengan materi yang diberikan di kelas.

\section{Pelaksanaan Pembelajaran}

\section{Membukan Pelajaran}

Saat membukanpelajaran, seorang guru hendaknya melakukan pengabsenan terlebih dahulu kepada siswa-siswanya.nTak jarang juga yang memberikan cerita inspirasi yang berkaitanndengan pembelajaran hari. Guru mata pelajarannAl-Qur'an Hadits di MTs Surya Buananbiasanya membuka pembelajaran dengan beroda, absennkehadiran dan menanyakan kabar peserta didik. Hal ini merupakannsesuatu yang wajib dilakukan ketika hendak memulai pembelajaran.

\section{Menyajikan Materi}

Dalam menyajikan materi, guru matanpelajaran Al-Qur'annHadits MTs Surya Buananmelakukan berbagai macam cara, baik dengan menggunakan metode, strategi, sumber dan media yangnbervariasi. Hal tersebut diperlukan 
agarnpembelajaran tidak kaku dan terjadi interaksi dua arah dan memungkinkan mencapaintujuan dari pembelajaran tersebut. Namun ketika pandeminmelanda, gurundituntut lebih maksimal dalam proses pembelajaranndaring tersebut.

\section{Menutup Materi}

Ketika guru menutupnpelajaran, hendaknya memberi penguatan atau review materi yang telah disampaikan agar pesertandidik dapat memahami secara menyeluruh. Biasanya ada yang malu bertanya padahal belum paham. Dalam hal ini, guru matanpelajaran Al-Qur'annHadits memberi penguatan materi yang telah disampaikan kepada pesertandidik di akhir pembelajaran serta review materi.

\section{Evaluasi Pembelajaran}

Evaluasi memilikinbeberapa bentuk, di antaranya: kuis, pilihan ganda, essay atau isian, mencocokan (mix andnmatch). Guru biasanya menggunakan pilihan ganda maupun essay sebagai bentuknevaluasi yang dirasa cukup untuk peserta didik. Dalam hal ini, guru mata pelajaran Al-Qur'annHadits menggunakan bentuk evaluasi berupa pilihan ganda pada beberapa evaluasi materi.

Strategi dalam Kamus Ilmiah Populer memiliki makna siasat, yaitu siasat untuk mendapatkan sesuatu. Strategi dalam pengertian sempit diartikan sebagai seni menggunakan kekuatan militer untuk mencapai tuuan-tujuan yang telah ditetapkan. Sedangkan strategi dalam arti luas diartikan sebagai seni (art) semua kekuatan. ${ }^{19}$

Strategi problem solving merupakan strategi yang digunakan guru baik dalam mata pelajaran umum maupun Agama. Strategi ini biasanya menekankan pada kemampuan berpikir tingkat tinggi, kemampuan penyelesaian masalah oleh peserta didik, kemampuan menemukan solusi serta menyampaikan pendapat maupun kesimpulan oleh dirinya sendiri. Peneliti menemukan bahwa strategi prblem solving dapat digunakan pada mata pelajaran agama Islam terutama bagi Al-Qur'an Hadits.

Strategi Problem Solving bukan hanya digunakan sebagai alternatif guru dalam mengembangkan keterampilan berpikir peserta didiknya, akan tetapi juga perperan penting pada kognitif dan membantu memahami masalah yang dihadapinya. Secara langsung, anak akan dituntut untuk mencari solusi yang ia anggap tepat untuk permasalahan tersebut, menanamkan anak untuk mencari

${ }^{19}$ Siti Khosiah, dan Rika Sa'diyah. ." Strategi Pembelajaran PAI Pada Peserta Didik Tuna Grahita Sekolah Dasar Kelas Awal di Sekolah Dasar Luar Biasa (SDLB) Pembina Tingkat I Cilandak Lebak Bulus Jakarta Selatan”. Jurnal Belajea LAIN Curup, Vol 2 No.1, 2017. hal. 4 
solusi dan kesimpulan sejak dini berfungsi pula sebagai bekal mengahadapi masalah kelak ketika dewasa.

\section{Kajian Terdahulu}

Rosmiati, Nim 10811001487, Jurusan Pendidikan Agama Islam, Fakultas Tarbiyah dan Keguruan, Universitas Islam Negeri Sultan Syarif Kasim Riau Pekanbaru, dengan judul "Penggunaan Metode Problem Solving (Pemecahan Masalah) Dalam Pembelajaran Al-Qur'an Hadits di Madrasah Aliyah Nurul Wathan Pasar Kembang Kecamatan Keritang Kabupaten Indragiri Hilir”. Fokus Penelitian ini adalah mengetahui efektif atau tidaknya penggunaan metode problem solving pada pembelajaran Al-Qur'an Hadits kepada siswa. ${ }^{20}$

Saepudin dkk, dalam Jurnal Manhaj, Vol 05, No 02, dengan judul "Inovasi Guru dalam Meningkatkan Proses Pembelajaran Al-Qur'an Hadits di MI Plus Ja-al Haq Kota Bengkulu”. Fokus penelitian ini adalah melakukan inovasi dalam mengajar pada sumber, media , metode kreatif serta keterampilan dalam mengajar, misalnya menggunakan metode proyek, kemudian metode sosiodrama dan metode problem solving, ketiga metode ini digunakan secara bergantian setiap empat kali pertemuan, sehingga siswa tidak bosan selama melakukan proses pembelajaran karena setiap kali pertemuan ada hal-hal baru yang diperoleh siswa. ${ }^{21}$

\section{KESIMPULAN}

Berdasarkan hasil temuan data di lapangan dapat disimpulkan: Perencanaan Pembelajaran Al-Qur'an Hadits melalui Strategi Problem Solving: perencanaan terdiri dari Rencana Pelaksanaan Pembelajaran (RPP) dan silabus. Kesesuaian materi Al-Qur'an Hadis sebagai Pedoman Hidup telah sesuai dengan apa yang ada di dalam silabus maupun RPP. Hal ini membuktikan profesionalitas seorang guru sebagai pendidik, menyiapkan materi beserta perangkatnya dapat berdampak pada hasil akhir serta proses pembelajaran di kelas.

Pelaksanaan Pembelajaran Al-Qur'an Hadits melalui Strategi Problem Solving: membuka pelajaran dengan memberi poin-poin penting dan review mater,

${ }^{20}$ Rosmiati,“ Penggunaan Metode Problem Solving (Pemecahan Masalah) Dalam Pembelajaran Al-Qur'an Hadits di Madrasah Aliyah Nurul Wathan Pasar Kembang Kecamatan Keritang Kabupaten Indragiri Hilir", (Skripsi Fakultas Tarbiyah dan Keguruan Universitas Islam Negeri Sultan Syarif Kasim Riau Pekanbaru, Pekanbaru 2012), hal. 28-33

${ }^{21}$ Saepudin dkk, "Inovasi Guru dalam Meningkatkan Proses Pembelajaran Al-Qur'an Hadits di MI Plus Ja-al Haq Kota Bengkulu” Jurnal Manhaj, Vol 05, No 02, (mei-agustus, 2017) hal. 5 
menyajikan materi kemudian menutup pelajaran dengan meninjau kembali. untuk pelaksanaan strategi problem solving pada materi Al-Qur'an Hadits dari hasil penelitian ini dinyatakan berhasil. Berdasarkan hasil wawancara, observasi dan dokumentasi, peneliti mendapatkan kesimpulan bahwa pembelajaran Al-Qur'an Hadits yang dinilai sulit menjadi lebih mudah saat guru menggunakan strategi problem solving.

Evaluasi Pembelajaran Al-Qur'an Hadits melalui Strategi problem solving: sebagai seorang guru, harus mengerti letak kesalahan anak didiknya. Anak tidak bisa mencapai Kriteria Ketuntasan Minimum pada nilainya bukan berarti kesalahannya, guru harus mengevaluasi apakah terdapat kesalahan pada diri guru tersebut saat menjelaskan materi atau tidak. Maka guru mata pelajaran Al-Qur'an Hadits telah berlaku sebagaimana mestinya dengan menerapkan sikap ma'fu (toleransi), dengan adaanya toleransi maka anak-anak akan diberi waktu untuk memperbaiki hasil evaluasinya walau tidak sempurna. Evaluasi yang dilaksanakan oleh guru mata pelajaran Al-Qur'an Hadits berupa pemberian tugas atau soal baru dan diberi tenggat waktu.

\section{BIBLIOGRAPHY}

Anggito, Albi dan Johan Setiawan. Metodologi Penelitian Kualitatif. (Sukabumi: CV Jejak, 2018)

Ar-Rasikh, "Pembelajaran Al-Qur'an Hadits di Madrasah Ibtidaiyah: Studi Multisitus padaa MIN Model Sesela dan Madrasah Ibtidaiyah At-Tahzib", Jurnal Penelitian Keislaman, Vol.15, No.1 (2019)

Fitrah ,Muh, Luthfiyah, Metodologi Penelitian: Penelitian Kualitatif, Tindakan Kelas \& Studi Kasus, (Sukabumi: CV Jejak, 2017)

Harmoni, "Implementasi Pembelajaran Al-Qur'an Hadits Terhadap Minat Belajar Peserta Didik", Jurnal Pemikiran dan Pengembangan Pembelajaran, Vol.2, No.1, (Januari-April)

Hasanah, Hasyim, “Teknik-teknik Observasi”, Jurnal at-Taqaddum, Vol 8, No.01, (2016)

Husein ,Saddam, Radiudin Alfian Sangadji, dan Laganti Salayar, "Urgensi Pembelajaran Al-Qur'an Hadist terhadap Prestasi Belajar Peserta Didik di MTs Nurul Ikhlas Kalapa Dua Seram Bagian Barat", Al-iltizam, Vol.3,No.1, (Mei 2018)

Isnu Hidayat, "50 Strategi Pembelajaran Populer” (Yogyakarta:2019)

Maros, Fadlun, dkk "Penelitian Lapangan (Field Research))" (Makalah Fakultas Ilmu Sosial dan Ilmu Politik Universitas Sumatera Utara, Sumatera 2016) 
Muttaqin, Chotibul dan Zaenal Arifin, "Babtsul Masail sebagai Problem Solving Method dalam Pembelajaran Fikih Kontekstual”, Attaqwa: Jurnal Ilmu Pendidikan Islam, Vol.16, No.1, (Maret 2020)

Nasrullah, Irja, "Resep Hidup Babagia Manurut Al-Qur'an", (Pustaka Alvabet: 2019)

Rika Sa'diyah, Siti Khosiah.” Strategi Pembelajaran PAI Pada Peserta Didik Tuna Grahita Sekolah Dasar Kelas Awal di Sekolah Dasar Luar Biasa (SDLB) Pembina Tingkat I Cilandak Lebak Bulus Jakarta Selatan".Jurnal Belajea IAIN Curup, Vol 2 No.1.(2017)

Rosmiati,“ Penggunaan Metode Problem Solving (Pemecahan Masalah) Dalam Pembelajaran Al-Qur'an Hadits di Madrasah Aliyah Nurul Wathan Pasar Kembang Kecamatan Keritang Kabupaten Indragiri Hilir", (Skripsi Fakultas Tarbiyah dan Keguruan Universitas Islam Negeri Sultan Syarif Kasim Riau Pekanbaru, Pekanbaru 2012)

Rukin, Metodologi Penelitian Kualitatif, (Takalar: 2019)

Saepudin dkk, "Inovasi Guru dalam Meningkatkan Proses Pembelajaran Al-

Qur'an Hadits di MI Plus Ja-al Haq Kota Bengkulu" Jurnal Manhaj, Vol 05, No 02, (mei-agustus, 2017)

Semiawan ,Conny.R., “Metode Penelitian Kualitatif” (Cikarang:2010)

Surur, Miftahus, dkk "Keefektifan Problem Solving Strategy (PSS) Untuk Meningkatkan Keterampilan Memecahkan Masalah pada Siswa SMP, Jurnal Pendidikan, Vol.1, No.11, (November 2016)

Suyadi, Hidayatul muamanah "Pelaksanaan Teori Belajar Bermakna David Ausebel Dalam Pembelajaran Pendidikan Agama Islam". Jurnal Belajea IAIN Curup. Vol 5. No.1(2020)

Syarbini, Amirulloh dan Sumantri Jamhari, "Kedabsyatan Membaca AlQur'an",(Bandung: 2012)

Zamana ,Millata dan Siti Rahmah, "Kreativitas Guru dalam Penerapan Metode Pembelajaran Al-Qur'an Hadits di MIN Rukoh Banda Aceh", Jurnal Tunas Bangsa, Vol.5, No.2, (Agustus 2018)

Zuraidah, Muslim Afandi. "Kesiapan, Gaya Belajar dan Keaktifan Siswa Pada Pembelajaran Pendidikan Agama Islam di SMPN Bangkinang Kota". Jurnal Belajea IAIN Curup. Vol 5. No 2. (2020) 
26 | Belajea: Jurnal Pendidikan Islam, Vol. 6, No. 1, 2021 